\title{
Marketing Strategy Study under E-commence Background
}

\author{
Xuan Wang \\ University of Science and Technology of Wuchang Business, Wuhan 430223, China
}

Keywords: E-commerce background, Marketing, Strategy study

\begin{abstract}
E-commerce is a kind of development of traditional commercial activities in the era of information. E-commerce as a new business mode is generating huge influence on people's production and life style. This paper studies the changes in marketing mode under e-commerce background, and proposes some problems in marketing activities under e-commerce background. On this basis, marketing strategy under e-commerce background is also proposed, in the hope of offering some beneficial reference for marketing strategy study under e-commerce background.
\end{abstract}

\section{Introduction}

Different from traditional business mode, the foundation of e-commerce establishment is an open network platform. In transaction activities, both parties do not need face-to-face talks and they can complete transaction through internet. In recent years, e-commerce has achieved great development with the progress of era, and brings new challenges to development of marketing industry. Under such situation, some measures should be adopted t0 change traditional marketing mode and establish a new marketing method in order to make marketing activity reach the expected objective.

\section{Changes in marketing mode under e-commerce background}

Marketing is a sales mode according to market development, and implementation of marketing must be based on market ${ }^{[1]}$. With the development of era, huge changes appear to market. Marketing should make proper adjustment according to market changes.

\section{Huge change in marketing conditions}

In traditional market transactions, transactions among enterprises own certain regional restrictions. However, the emergence of internet changes the passive situation in traditional trade mode. Transactions among enterprises are not limited by time and space. Enterprises can trade around the clock without regional restriction via internet. Under such case, some unnecessary links in enterprise marketing campaign may be omitted, which can reduce cost for marketing activity and bring more profits for enterprise development. Secondly, payment mode of trading activity also alters greatly. Such paperless payment mode becomes more convenient and safer, and offers convenience for implementation of large-scale trade business, compared with traditional cash payment mode. Finally, marketing relationship between enterprises and consumers also alter greatly. In such case, bidirectional trading relation is established between enterprises and consumers. Consumers can not just use commodities, but also evaluate commodity quality and make feedback to enterprises.

\section{Changes in consumers' behaviors}

Apart from great changes in marketing conditions, consumers' behaviors undergo great changes. For example, in traditional marketing mode, marketing mainly aims at some specific consumer group. Although such marketing mode achieves some success, these consumers are often some temporal customers and will seldom consume for a long time. However, under e-commerce background, many consumers' consumption behaviors are achieved under the influence of other consumers, without the need of introduction by special marketing personnel. Consumers' purchase becomes more irrational. Consumers often need to judge whether to consume through mutual comparison, while the function of marketing personnel becomes very limited.

\section{Changes in marketing concept}

E-commerce is a commercial activity based on internet which makes enterprise transactions become more open and transparent. To gain more continuous development space, enterprises need to 
stick to the principle of "customer benefit supreme" in the development process, and closely connect their own development and customers' interests so as to form marketing concept of "service supreme” .

\section{Some problems of marketing under e-commerce conditions}

Internet is a double-edged sword. It brings both convenience and some problems. E-commerce is internet-based business mode. In such case, it is necessary to analyze the problems of marketing under e-commerce conditions.

\section{Supporting services cannot achieve coordinated development}

Under e-commerce background, enterprise marketing work in the early stage is ready, but when enterprises send commodities, some supporting services related to marketing cannot reach expected objective $^{[2]}$. It is common to see logistics service cannot reach the requirement. For example, goods delivery speed of some logistics companies is relatively slow. Secondly, some commodities are damaged in the transportation process due to various causes. All these will generate adverse effects on marketing campaign. In addition, in some large shopping festivals, network system breakdown will result in cancellation of a great number of orders in some e-commerce activities. For example, network system breakdown happened during "11.11 shopping festival”.

\section{Some enterprises lack fundamental honesty}

For market economy, honesty is the precondition and foundation of market economy operation. "Taobao" is taken for example. If the seller's credit rating is very high, more buyers will be abstracted. But, in actual e-commerce operation process, some sellers adopt some extreme methods to boost credit. For instance, some boost their credit rating through scalping, or force customers to improve credit rating level for them through cash back. However, once consumers buy commodities, some merchants will use some commodities with poor quality to deceive consumers.

\section{Networked marketing mode is single}

With the implementation of e-commerce platform, some enterprises place the center of operation on network and marketing is mainly achieved through website promotion and email. Of course, some enterprises interpret connotation of network transaction only with the help of website platform. In such case, marketing under e-commerce background will become increasingly single.

\section{Enterprise marketing strategy analysis under e-commerce background}

E-commerce has become an irreversible development tendency. To conform to development trend of the era, it is necessary to combine development features of e-commerce and formulate marketing strategy suitable for e-commerce development.

\section{Invest in some supporting service facilities}

Supporting service facilities related to e-commerce are diversified. To improve e0commerce marketing level, it is necessary to invest in supporting services of e-commerce first ${ }^{[3]}$. Efforts should be made at multiple directions for supporting services of e-commerce. Firstly, enterprises should establish cooperation with logistics companies. First of all, aiming at slow delivery speed of logistics companies, enterprises should communicate with logistics companies and boost delivery speed of logistics enterprises as far as possible. Secondly, in goods delivery process, logistics companies should do safety guarantee well to make sure goods have no quality problem in transportation process. Finally, since logistics companies are not allowed to unwrap the package to check goods, enterprises and websites should negotiate to find out a suitable method. Of course, once no agreement can be reached, the problems may be solved through legal approach. Secondly, e-commerce companies should enhance construction of network hardware facilities, adopt the server with good quality and strong operation function so that the server can cope with powerful customer impacts and offer better services for customers. Thirdly, enterprises should do after-sale work well. Once problems occur, it is required to communicate with consumers in time and propose a satisfying solution so as to win the approval of consumers. Fourthly, relevant government sectors should protect development of 
e-commerce, enhance legal construction and offer a favorable order for better development of e-commerce platform.

\section{Reposition product features, marketing purpose and range}

With the change of era, e-commerce business mode also alters greatly. Enterprises also need to continuously perfect and develop enterprise marketing mode under e-commerce background ${ }^{[4]}$. Firstly, enterprises need to consider changes in consumer demand. Under general background of e-commerce, transaction range of buyers and sellers has been no longer limited to enterprise products. Enterprises should guarantee commodity quality and service attitude while providing commodities for consumers. In addition, the speed of logistics enterprises should be considered in enterprise marketing. Through such method, enterprise consumer group will be stabilized to some extent. To be more specific, enterprises need to take interactive marketing mode in the operation process, keep mutual communication with consumers, regard improving the credit of consumer group as a favorable marketing means and make consumers open larger market for enterprises through keeping good relationship with consumers.

Rapid progress of e-commerce platform makes social function of enterprises expand continuously. Enterprises' profit mainly comes from social consumers. If enterprises attach great importance to their social responsibility in development and participate in some social activities for public good, enterprises will establish favorable social image, win social approval and expand larger consumer market for enterprises. Of course, the precondition of these marketing activities is that enterprises can provide consumers with some satisfying services. Therefore, under e-commerce background, enterprise marketing not just needs scientific management level, but also needs to undertake some social responsibilities. Hence, in the era of e-commerce, enterprises cannot only sell commodities in marketing service, but should carry out other various commodity and service types. In particular, enterprises' after-sale service attitude and quality will usually generate important influence on enterprises. So, in the era of e-commerce, enterprises need to regard express delivery service quality, enterprise service attitude, service quality and after-sale service as important links of marketing business.

\section{Reform marketing mode}

Significant development of e-commerce makes trading mode change greatly. To adapt market changes, enterprises need to adopt multiple modes to make corresponding adjustment of marketing mode.

Search engine marketing strategy

Under normal conditions, consumers often look for commodities through search engine ${ }^{[5]}$. According to consumers' consumer psychology, consumers will choose the links with large click rate. In such case, the ranking of enterprise commodities in search engine will generate corresponding influence on commodity sale. Thus, marketing under e-commerce conditions must establish marketing work related to search engine. For current e-commerce development, many enterprises improve commodity click rate through cooperation with search engine enterprises. So, enterprises just need to pay certain funds to search engine companies to register key words on the website. On this basis, enterprises can participate in key word rating.

\section{E-mail marketing strategy}

For e-commerce business, media means is a good approach. If enterprises' product information is added in email, much marketing information may be provided for customers. With email, enterprises may search user type information except releasing product information. On this basis, enterprises may formulate suitable marketing ways in allusion to different customer features and optimize the relationship between e-commerce merchants and customers to some extent so as to make e-commerce merchants gain more information from customers.

\section{Network brand marketing}

E-commerce is a fair and transparent platform. In e-commerce platform, enterprises can compete fairly regardless of the scale and industry, and the status of various enterprises is equal. E-commerce enterprises apply various marketing means such as network advertising and media advertising to publicize their products so as to bring expansive development space for enterprises. Moreover, it is 
found through comparing other marketing modes that, internet marketing spends less. Besides, market response gained by enterprises should be quite good. Based on such reason, network brand marketing is welcomed by many enterprises, and occupies an important status in social and economic development.

Enhance enterprise honesty construction

Honesty is the life of an enterprise. Meanwhile, it is the precondition and foundation of long-term development of enterprises. In e-commerce environment, enterprises should pay more attention to honesty education. Firstly, enterprises should completely eradicate false advertising behavior and ensure product quality safety. Secondly, website should prohibit the behavior of credibility scalping.

\section{Conclusions}

With the progress of era, e-commerce enters unprecedented prosperous development situation. To conform to development trend of era, marketing mode under traditional conditions also should conform to development trend of era and make corresponding changes. According to the need of market development, it is required to formulate marketing mode based on e-commerce background so as to improve enterprise competitiveness.

\section{References}

[1] Xiang Wen, Thought of telecommunication marketing strategy innovation under internet background. Business, 2014(10):143-143.

[2] Tian Yuan, On influence of e-commerce on marketing of State-owned Commercial Bank - case study of Industrial and Commercial Bank of China. Chinese and Foreign Entrepreneurs, 2015(1):93-96.

[3] Zong Cong, Analysis of marketing strategy under Web2.0 era. Economic \& Trade Update, 2011(17):147-148.

[4] Du Kexin, On promotion effect of e-commerce on marketing campaign of modern enterprises. Business Economics, 2012(8):79-80.

[5] Liu Xiaoxiao, Thought of aviation marketing strategy in e-commerce era. Air Transport \& Business, 2014(10):41-42. 